$11-1-1999$

\title{
The current state of practice administration curricula in U.S. dental schools.
}

\author{
Brian M. Lange \\ University of Nebraska Medical Center, blange@unmc.edu \\ David G. Dunning \\ University of Nebraska Medical Center, ddunning@unmc.edu \\ Denise C.L. Stewart \\ University of Pennsylvania \\ Jack L. Hardage \\ University of Texas Health Science - San Antonio
}

Tell us how you used this information in this short survey.

Follow this and additional works at: https://digitalcommons.unmc.edu/cod_articles

Part of the Dentistry Commons

\section{Recommended Citation \\ Lange, Brian M.; Dunning, David G.; Stewart, Denise C.L.; and Hardage, Jack L., "The current state of practice administration curricula in U.S. dental schools." (1999). Journal Articles: College of Dentistry. 18. https://digitalcommons.unmc.edu/cod_articles/18}

This Article is brought to you for free and open access by the College of Dentistry at DigitalCommons@UNMC. It has been accepted for inclusion in Journal Articles: College of Dentistry by an authorized administrator of DigitalCommons@UNMC.For more information, please contact digitalcommons@unmc.edu. 


\title{
The Current State of Practice Administration Curricula in U.S. Dental Schools
}

\author{
Brian M. Lange, Ph.D.; David G. Dunning, Ph.D.; Denice C.L. Stewart, D.D.S., M.H.S.A.; \\ Jack L. Hardage, D.D.S.
}

Dr. Lange is Professor and Chair with the Department of Dental Practice Management, University of Nebraska Medical Center College of Dentistry; Dr. Dunning is Associate Professor and Vice Chair with the Department of Dental Practice Management, University of Nebraska Medical Center College of Dentistry; Dr. Stewart is Assistant Professor and Interim Chair, Dental Care Systems, University of Pennsylvania School of Dental Medicine; and Dr. Hardage is Associate Professor and Director of the Division of Practice Dynamics, University of Texas Health Science Center at San Antonio Dental School. Direct correspondence and requests for reprints to Brian M. Lange, UNMC College of Dentistry, 40 ${ }^{\text {th }}$ \& Holdrege Streets, Lincoln NE 68583-0754; 402472-1274 phone; 402-472-6681 fax; blange@unmc.edu e-mail.

$\mathrm{O}$ ver the last twenty-five years, the teaching of practice administration/management to predoctoral dental students has appeared to undergo significant change. In the late 1970 s, articles on practice management in the Journal of Dental Education encouraged all dental schools to develop and expand practice management curriculum. ${ }^{1,2,3}$ The focus was to prepare the new dentist for the rigors of private practice, usually assumed to be a solo or small group practice.

By 1980 the American Association of Dental Schools (AADS) published curricular guidelines for the teaching of practice management. ${ }^{4}$ In 1984 the first comprehensive practice management curriculum study of all accredited dental schools helped establish a baseline for practice management curricula. ${ }^{5}$ In 1985 revised practice management guidelines were published. ${ }^{6}$

A 1992 study used a survey instrument that focused on the seven major areas of the 1985 practice administration curriculum guidelines: practice goals and plans; evaluation; decision making and control; patient care management; office systems; personnel management; quality assurance; and practice building and marketing. ${ }^{7}$ The authors concluded that little had changed from the 1985 study and that practice administration curricula were mature and secure in an era of decreasing availability in curricular time.

The last decade has seen a myriad of key changes related to practice management. Also, in 1993, practice management curriculum guidelines were revised, and in 1998 the American Dental Association revised accreditation standards to include competencies. Eight of the fifteen content/skill specific competencies (i.e., 2-12 through 2-26), relate to practice management: two for behavioral science, two for practice management, three for ethics/professionalism, and one for information technology as applied in dental practice. ${ }^{8}$ Rising educational costs and concomitant student indebtedness, increasing government regulations, proliferating technology, growing costs of establishing/purchasing a practice, expanding managed care, and the growing number of large corporately owned dental practices with relatively high beginning salaries plus incentives have all placed extraordinary strain on schools to prepare graduates to practice dentistry.

The status of practice management curricula in U.S. dental schools has not been assessed since 1990. This study was undertaken to determine how schools are addressing the challenges in practice management instruction, particularly the extent to which topics are being taught and the methods of instruction being utilized.

\section{Methods}

The 1993 curriculum guidelines, the practice management/administration curriculum studies of 1984 and 1992, and the practice administration literature were all utilized as tools to develop a twopart, eighteen-item questionnaire. This questionnaire defined practice management as "the body of knowledge that prepares dental students to understand and utilize economic, marketing, financial, sociological, technological, legal, and ethical perspectives to manage a dental practice." The survey focused on specifying hours taught for each topic/area, educational techniques used to teach the material, the year(s) the material was provided, and an assessment of how 
faculty rated the instruction of this material. A second part of the survey consisted of two questions dealing with faculty full-time equivalencies assigned to teach practice administration and the monetary resources available to enhance the practice management curriculum. The questionnaire was reviewed by faculty at three dental schools and their recommendations were incorporated. No pilot data were collected.

In the fall of 1998 the questionnaire was sent to the individual(s) responsible for teaching practice administration at each school. These individuals had been identified by the AADS section on practice administration by direct contact with all U.S. dental schools. A follow-up questionnaire or fax was sent to non-respondents. Three weeks after the second mailing, phone calls were made to non-respondents encouraging their participation.

Data from the 1998 survey were compared to those of the 1984 survey. Frequencies, means, and standard errors were calculated.

\section{Results}

Completed questionnaires were received from forty-three of fifty-two U.S. dental schools for a response rate of 82.6 percent. Two dental schools were exempted from the questionnaire process. A newly formed school had not yet developed all of its practice administration curriculum, and the other school was in the process of closing.

The total practice administration contact hours provided during all four years of dental school averaged seventy, with a range of 11.5 to 244 (Table 1). As shown in Figure 1, the majority of the total practice administration curriculum was taught via the lecture format. The major subjects taught and the average contact hours devoted to each are shown in Table 2.

Respondents reported a mean full-time equivalent for faculty assigned to practice administration of 0.54 with a standard error of 0.09 and a range of $0-2.8$. The correlation between full-time equivalency and total hours of instruction was $0.33(\mathrm{p} .=0.03)$,

Table 1. Total contact hours of practice administration

$\begin{array}{lcc}\text { Year } & \text { Mean } & \text { Range } \\ 1984 & 88 & 16-632 \\ 1998 & 70 & 11.5-244\end{array}$

indicating a positive association between faculty resource allocation and quantity of instruction in practice management. Thirty-six percent (fifteen) of the reporting schools indicated resources for guest speakers and purchases of software and texts were available. In addition to monies for committed FTEs, the mean dollar amount allocated for these activities was $\$ 5,477$ per year (standard error of $\$ 3,490$; range of $\$ 250-\$ 40,000)$.

Respondents were asked to rate the adequacy of the coverage in each topic/subject area using a simple scale of $1=$ unsatisfactory, $2=$ satisfactory, or $3=$ outstanding. Table 3 reports means and percentages of response for each topic area. The lowest reported mean was 1.71 for inventory control.

\section{Discussion}

When the practice administration curriculum topics of the 1984 and the 1998 study are compared (Figure 1), it becomes evident that dental educators are relying more on the lecture format and less on clinical experiences or small groups to teach subject material. Also, somewhat surprising in the age of technology is that so little is done with lab/simulations to teach practice administration. The loss of dental auxiliary utilization/team programs coupled with the resultant loss in staff funding may offer a partial explanation for the increased reliance on the lecture format. The heavy dependency on that format in many instances may be out of necessity. Only

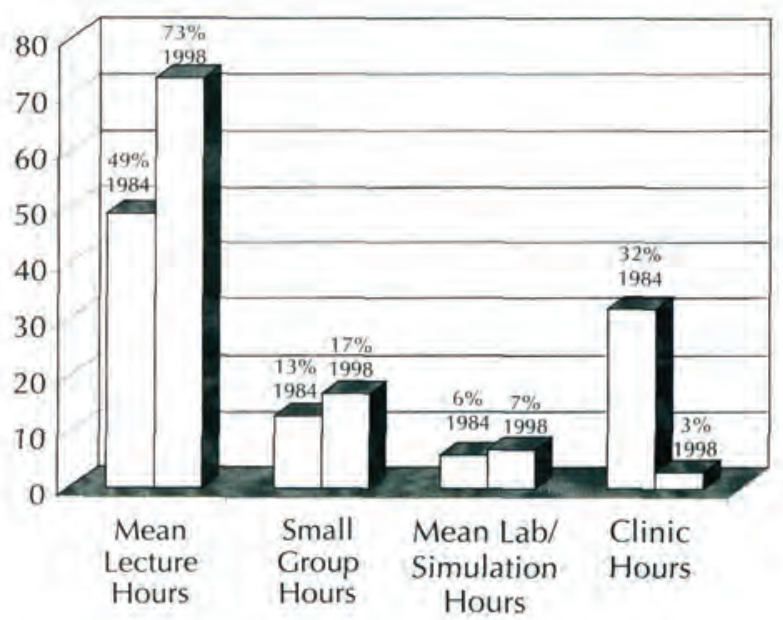

Figure 1. Total practice administration curriculum 
Table 2. Practice administration curriculum comparison, 1998 vs. 1984

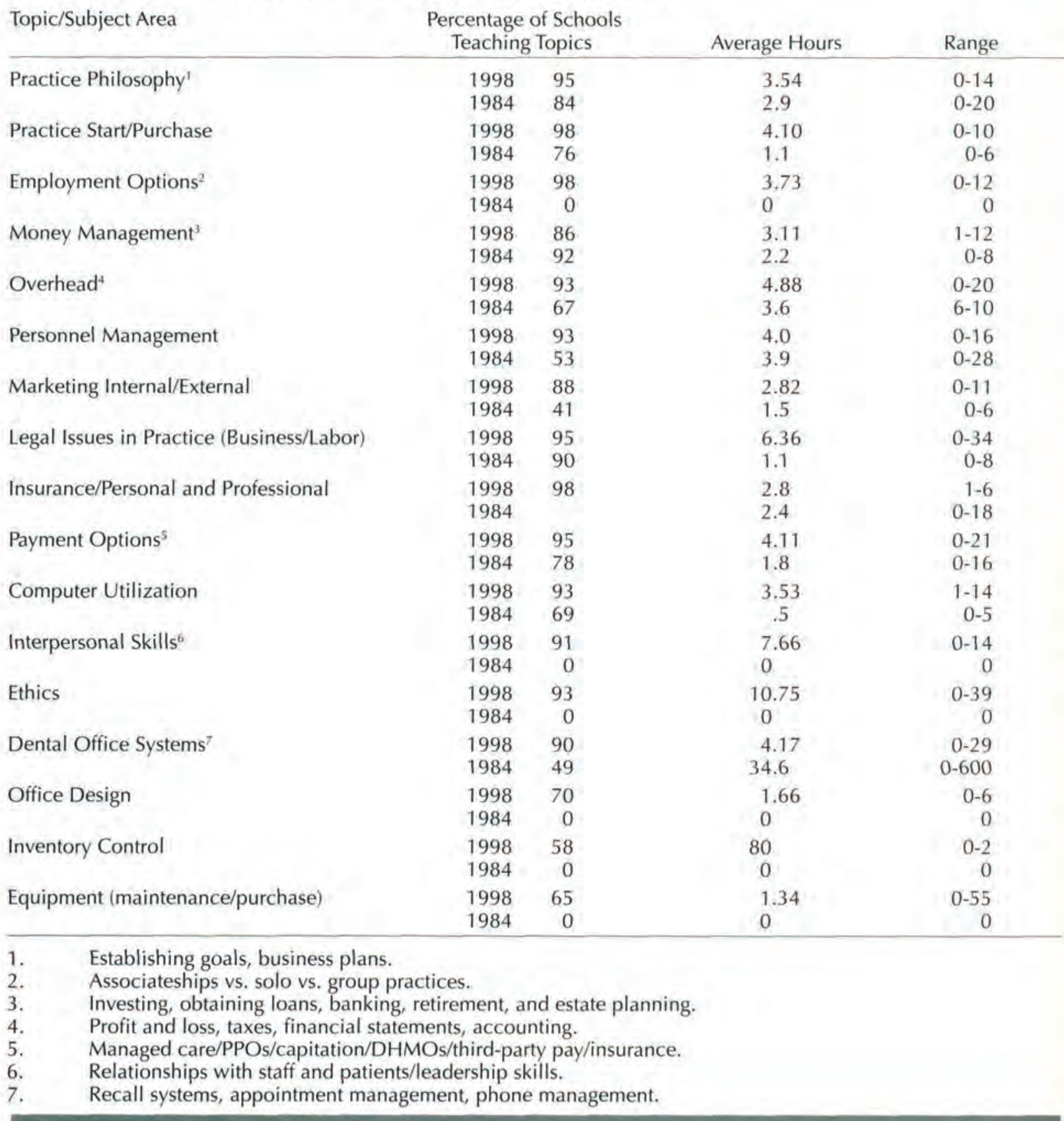

36 percent of reporting schools received financial support, beyond faculty positions for practice administration curriculum. Also, a number of schools hire consultants to teach part or all of their practice administration curriculum. With mean full-time equivalent faculty assignment of .54 (standard error of .09 and range of $0-2.8$ ), it is apparent that most faculty teaching practice administration have other responsibilities or teach part-time.
A comparison of practice administration curriculum content for 1984 with that for 1998 reveals a number of curricular shifts. Topics such as group practice, ethics, and interpersonal skills were not a part of the vocabulary in the curriculum of 1984. In 1984 it appears that such topics were taught as a function of clinical-based experiences. The topics of economics, organizational behavior, and statistics have 
Table 3. Mean Rating of Instruction

Topic/Subject Area

\begin{tabular}{|c|c|c|c|c|c|c|c|}
\hline $\begin{array}{l}\text { Mean } \\
\text { of Instr } \\
\text { (standar }\end{array}$ & $\begin{array}{l}\text { Rating } \\
\text { uction } \\
\text { d error) }\end{array}$ & Unsa & isfactory & Satis & actory & Outst & anding \\
\hline 2.15 & $(.08)$ & 3 & $(8 \%)$ & 27 & $(69 \%)$ & 9 & $(23 \%)$ \\
\hline 2.25 & (.08) & 2 & $(5 \%)$ & 27 & $(67.5 \%)$ & 11 & $(27.5 \%)$ \\
\hline 2.21 & $(.10)$ & 5 & $(12.5 \%)$ & 22 & $(55 \%)$ & 13 & $(32.5 \%)$ \\
\hline 2.08 & $(.10)$ & 5 & (14\%) & 23 & $(64 \%)$ & 8 & $(22 \%)$ \\
\hline 2.03 & (.11) & 8 & $(20.5 \%)$ & 22 & $(56.5 \%)$ & 9 & $(23 \%)$ \\
\hline 2.03 & (.09) & 5 & $(14 \%)^{\prime}$ & 26 & $(70 \%)$ & 6 & $(16 \%)$ \\
\hline 1.94 & (.11) & 8 & $(23 \%)$ & 21 & $(60 \%)$ & 6 & $(17 \%)$ \\
\hline 2.31 & $(.10)$ & 4 & $(10 \%)$ & 19 & (49\%) & 16 & $(41 \%)$ \\
\hline 2.11 & $(.09)$ & 4 & $(11 \%)$ & 26 & $(68 \%)$ & 8 & $(21 \%)$ \\
\hline 2.03 & $(.08)$ & 4 & $(11 \%)$ & 29 & $(76 \%)$ & 5 & $(13 \%)$ \\
\hline 1.88 & $(.10)$ & 9 & $(24 \%)$ & 24 & $(63 \%)$ & 5 & $(13 \%)$ \\
\hline 2.14 & (.11) & 6 & $(16 \%)$ & 20 & (52.5\%) & 12 & $(31.5 \%)$ \\
\hline 2.18 & (.11) & 5 & $(13 \%)$ & 21 & $(55 \%)$ & 12 & $(32 \%)$ \\
\hline 1.92 & (.10) & 8 & $(21 \%)$ & 25 & $(66 \%)$ & 5 & $(13 \%)$ \\
\hline 1.88 & (.11) & 9 & $(27 \%)$ & 19 & $(58 \%)$ & 5 & $(15 \%)$ \\
\hline 1.71 & (.10) & 9 & $(32 \%)$ & 18 & $(64 \%)$ & 1 & $(4 \%)$ \\
\hline 1.88 & (.10) & 7 & $(22 \%)$ & 22 & $(69 \%)$ & 3 & $(9 \%)$ \\
\hline
\end{tabular}

\begin{tabular}{|c|c|c|c|c|}
\hline Practice Philosophy' & 2.15 & $(.08)$ & 3 & \\
\hline Practice Start/Purchase & 2.25 & $(.08)$ & 2 & \\
\hline Employment Options² & 2.21 & (.10) & 5 & \\
\hline Money Management ${ }^{3}$ & 2.08 & $(.10)$ & 5 & \\
\hline Overhead $^{4}$ & 2.03 & (.11) & 8 & \\
\hline Personnel Management & 2.03 & $(.09)$ & 5 & \\
\hline Marketing/Internal-Externál & 1.94 & $(.11)$ & 8 & \\
\hline Legal Issues in Practice & 2.31 & (.10) & 4 & \\
\hline Insurance/Personal-Professional & 2.11 & $(.09$ & 4 & \\
\hline Payment Options ${ }^{5}$ & 2.03 & $(.08)$ & 4 & \\
\hline Computer Utilization & 1.88 & $(.10)$ & 9 & \\
\hline Interpersonal Skills ${ }^{6}$ & 2.14 & (.1 & 6 & \\
\hline Ethics & 2.18 & (.11) & 5 & \\
\hline Dental Office Systems ${ }^{7}$ & 1.92 & (.10) & 8 & \\
\hline Office Design & 1.88 & (.11) & 9 & \\
\hline Inventory Control & 1.71 & (.10) & 9 & \\
\hline Equipment Maintenance/Purchase & 1.88 & $(.10)$ & 7 & \\
\hline \multicolumn{5}{|c|}{$\begin{array}{ll}\text { 1. } & \text { Establishing goals, business plans. } \\
\text { 2. } & \text { Associateships vs. solo vs. group practices. } \\
\text { 3. } & \text { Investing, obtaining loans, banking, retirement, and estate planning } \\
\text { 4. } & \text { Profit and loss, taxes, financial statements, accounting. } \\
\text { 5. } & \text { Managed care/PPOs/capitation/DHMOs/third-party pay/insurance, } \\
\text { 6. } & \text { Relationships with staff and patients/leadership skills. } \\
\text { 7. } & \text { Recall systems, appointment management, phone management. }\end{array}$} \\
\hline
\end{tabular}

either been dropped from curricula or folded into other topics or subject areas.

The percentage of reporting dental schools giving more curriculum time to managed care/PPOs, capitation/DHMOs, practice start/purchase, overhead/profit loss, personnel management, marketing, and dental office systems have increased by a minimum of 15 percent to as much as 47 percent. The most dramatic reported curriculum change between 1984 and 1998 occurs in the topic of dental office systems (see Table 2). Dental office systems were defined in the questionnaire as recall, quality assurance, office telephone management, appointment book control, etc. The average contact hours reported in 1984 was 34.6 with a range of $0-600$. The 1998 reported results shows 4.17 average contact hours with a range of $0-29$. This decrease from 1984 to 1998 is dramatic and accounts for most of the difference in reported contact hours, from 88 in 1984 to 70 in 1988 (see Table 1). No doubt the difference would be greater except that virtually all other reported topics were given more didactic curriculum time in 1998. It may also be possible that respondents were unaware of or unable to quantify clinical instruction directed to specific practice management topics. Consequently, the actual numbers of contact hours may be higher. However, the 1984 respondents recommended adding subjects, increasing the mean number of subjects, and increasing the contact hours by nine. The 1998 participants report about the same number of topics and eighteen fewer contact hours. The reduction in contact hours is somewhat alarming given that the practice of dentistry has become more not less complicated by requirements such as OSHA standards or Americans with Disabilities compliance.

Both the 1998 and the 1984 studies show that most practice management teaching is concentrated in the last two years of the curriculum. Across all topics, this study indicated that the percentage of practice administration curriculum taught only in the third year is 18 percent on average, with 55 percent target; only in the fourth year and 14 percent in both the third and fourth years. Overall, then, approximately 87 percent of practice administration is taught in the three and/or four years. The new accreditation guidelines will place pressure on dental schools to 
ensure that students have multiple exposures to practice administration at various points in their curriculum. Dental school administrators and faculty will need to think about how to better integrate practice administration subjects throughout the four-year curriculum and expand teaching to include lab and clinical experiences.

The current emphasis on practice management may be insufficient to prepare graduates as well as satisfy practice management-weighted competency standards. It is arguable that students can achieve "competence" in eight specific practice administration-related accreditation standards with, on average, seventy hours of instruction. Based on the 1998 American Dental Association student survey, 51 percent of dental graduates immediately enter private practice upon graduation as owners, partners or associates. ${ }^{9}$ That percentage is only eight points lower than reported in 1984 by the American Dental Association. ${ }^{10}$

A typical undergraduate business major earning a bachelor's degree will experience about 825 hours of instruction(@55 credit hours in business alone $\mathrm{x} 15$ hours of instruction for each credit hour). By comparison, dental students receive only 8.5 percent of this instruction ( 70 divided by 825 hours). Perhaps this accounts in part for why $30-40$ percent of students typically check that "inadequate" time is devoted to practice management in the curriculum in the ADA annual student survey. The curriculum resources directed to teaching practice administration are disproportionate to the increasing emphasis placed on the content and discussed outcomes.

Beyond the obvious results presented in the tables, a very critical observation from the results can be made. It is clear that there are few "average" schools in practice management instruction, at least in terms of hours offered. In fact, schools separate somewhat into "haves" and "have nots": 42 percent of schools offer instructional hours two or more standard errors below the mean ( $<57$ hours); 33 percent of schools offer instructional hours two standard errors or more above the mean ( $>82$ hours). This leaves only 25 percent around the mean $+/$ - two standard errors. Obviously, the schools providing $<57$ hours have a much greater challenge in preparing graduates for practice and in satisfying accreditation site visitors.
Survey-based research suffers from several limitations, as does this study. Self-reported data may be overly optimistic, hours of instruction may not reflect actual clock hours, and results could be affected by the 17 percent of schools that choose not to participate. Data may understate the total practice administration curriculum since some faculty may not be aware of related material offered by other departments. Still, the data indicate a disturbing trend toward fewer hours of instruction, based heavily on lecture, and with more dependence on part-time and or guest lecturers in a time of increasing complexity in the management of dental practices.

\section{Acknowledgments}

We thank all survey respondents.

\section{REFERENCES}

1. American Dental Association Council on Dental Education. Dental education in the United States. Chicago: American Dental Association, 1977.

2. Reisman A, Emmons H, Mareto S, Rivaud J, and Green J. Dental practice management: a new tool for teaching practice management. J Dent Educ 1977;41:262-7.

3. Domer LR, Berger PK, and Wallace MJ. Designing and implementing relevant courses in dental management. J. Dent. Educ: $1976 ; 40: 552-55$.

4. Shard, H.A., et al. American association of dental schools curricular guidelines for practice management. J Dent Educ: 1980;44:550-3.

5. Abbott LJ, Forman G, Bauer LB. Practice management instruction in North American dental schools, 1983-84. J. Dent. Educ: 1984;48:674-8.

6. American Association of Dental Schools. Curricular guidelines for practice administration. J Dent Educ 1986;50:236-40.

7. Manski RJ, et al. Status of practice administration curricula. J Dent Educ 1992;56:346-8.

8. Commission on Dental Accreditation. Self-study guide for the evaluation of a dental education program in the United States. Chicago: American Dental Association, January 1998.

9. Survey of dental school seniors, 1998 graduating class. Chicago: American Dental Association, 1999.

10. Survey of dental school seniors, 1984 graduating class. Chicago: American Dental Association, 1985. 